\title{
Developing a Preliminary Definition and Domains of Flare in Knee and Hip Osteoarthritis (OA): Consensus Building of the Flare-in-OA OMERACT Group
}

\author{
Francis Guillemin (1D, Camille Ricatte (D), Annica Barcenilla-Wong (i), Amandine Schoumacker, \\ Marita Cross (D), Camille Alleyrat, Thomas Buttel, Michel Cembalo, Hakima Manseur, \\ Hema Urban (1), Bruno Fautrel (1D, Philip G. Conaghan (1), Gillian Hawker (D), \\ Claudia Rutherford (1), Lyn March (D), Elisabeth Spitz (D), and David J. Hunter (1)
}

\begin{abstract}
Flare in knee and hip osteoarthritis (OA) is more than just an exacerbation of pain. Unstructured, semistructured, and focus group interviews followed by Delphi surveys with patients and health professionals (HP) generated candidate domains of an OA flare. Content analysis of interviews with 29 patients and $16 \mathrm{HP}$ extracted 180 statements, which were grouped into 9 clusters. Delphi consensus with 50 patients (Australia, Canada, and France) and $116 \mathrm{HP}$ (17 countries on 4 continents) identified 5 flare domains: pain, swelling, stiffness, psychological aspects, and effect of symptoms. Elements for a preliminary definition of an OA flare are proposed. Registered at clinicaltrials.gov NCT02892058. (First Release May 15 2019; J Rheumatol 2019;46:1188-91; doi:10.3899/jrheum.181085)
\end{abstract}

Key Indexing Terms:

OMERACT FLARE OSTEOARTHRITIS HIP KNEE DOMAIN

From the INSERM, CIC 1433 Clinical Epidemiology; Université de Lorraine, APEMAC unit, MICS team, Nancy; Université de Lorraine, APEMAC unit, EPSAM team, Metz; Sorbonne Université, GRC 08; AP-HP, Rheumatology Department, Pitié-Salpétrière Hospital, Paris, France; University of Sydney, Institute of Bone and Joint Research, Kolling Institute; Rheumatology Department, Royal North Shore Hospital; Inner West Psychology; Faculty of Science, School of Psychology, and Faculty of Medicine and Health \& Nursing School, University of Sydney, Sydney, Australia; Leeds Institute of Rheumatic and Musculoskeletal Medicine, University of Leeds; UK National Institute for Health Research (NIHR) Leeds Biomedical Research Centre, Leeds, UK; Department of Medicine, University of Toronto, Toronto, Ontario, Canada.

This work was supported by a grant from Association Française de Lutte Anti Rhumatisme - France Rhumatisme (France) and the Kolling Foundation (Australia). This work was endorsed by OMERACT and Osteoarthritis Research Society International and by the STPR Group in Rheumatology in France. PGC is supported in part by the UK NIHR Leeds Biomedical Research Centre. The views expressed are those of the authors and not necessarily those of the UK National Health Service, the NIHR, or the Department of Health. GH receives salary support as the Sir John and Lady Eaton Professor and Chair of Medicine at the University of Toronto.

F. Guillemin, MD, PhD, INSERM, CIC 1433 Clinical Epidemiology, and Université de Lorraine, APEMAC - MICS; C. Ricatte, MSc, Université de Lorraine, APEMAC - EPSAM; A. Barcenilla-Wong, PhD, University of Sydney, Institute of Bone and Joint Research, Kolling Institute, and Rheumatology Department, Royal North Shore Hospital; A. Schoumacker, MSc, Université de Lorraine, APEMAC - EPSAM; M. Cross, PhD, University of Sydney, Institute of Bone and Joint Research, Kolling Institute, and Rheumatology Department, Royal North Shore Hospital; C. Alleyrat, MSc, Inserm, CIC 1433 Clinical Epidemiology; T. Buttel, MA, University of Sydney, Institute of Bone and Joint Research, Kolling Institute, and Rheumatology Department, Royal North Shore Hospital, and Inner West Psychology; M. Cembalo, PhD, Frouard, France; H. Manseur, MSc, INSERM, CIC 1433 Clinical Epidemiology; H. Urban, MBiomedSc, University of Sydney, Institute of Bone and Joint Research, Kolling Institute, and Rheumatology Department, Royal North Shore Hospital; B. Fautrel, MD, PhD, Sorbonne Université, GRC 08, and AP-HP,
Rheumatology Department, Pitié-Salpétrière Hospital; P.G. Conaghan, $M D, P h D$, Leeds Institute of Rheumatic and Musculoskeletal Medicine, University of Leeds, and NIHR Leeds Biomedical Research Centre; G. Hawker, MD, PhD, Department of Medicine, University of Toronto; C. Rutherford, PhD, Faculty of Science, School of Psychology, University of Sydney, and Faculty of Medicine and Health \& Nursing School, University of Sydney; L. March, MD, University of Sydney, Institute of Bone and Joint Research, Kolling Institute, and Rheumatology Department, Royal North Shore Hospital; E. Spitz, PhD, Université de Lorraine, APEMAC - EPSAM; D.J. Hunter, MBBS, PhD, FRACP, University of Sydney, Institute of Bone and Joint Research, Kolling Institute, and Rheumatology Department, Royal North Shore Hospital.

Address correspondence to Dr. F. Guillemin, EA 4360 APEMAC, School of Public Health - BP 20999, 54500 Vandoeuvre-les-Nancy, France.

E-mail:francis.guillemin@univ-lorraine.fr

Accepted for publication March 7, 2019.

Knee and hip osteoarthritis (KHOA) ranked as the 12th highest contributor to global disability in $2016^{1}$, with an age-standardized prevalence of $3.8 \%$ and $0.85 \%$ for knee and hip, respectively ${ }^{2}$. The most common symptoms associated with OA are pain, stiffness, and fatigue, which can flare during the evolution of this chronic condition.

Recent literature has shown that flare in KHOA is more than just an exacerbation of pain. Murphy, et $a l^{3}$ identified it by quality, timing of symptoms, antecedents, and consequences. Our literature review highlighted the wide variation in the definitions of OA flare and the lack of a valid measurement instrument integrating the patient perspective ${ }^{4,5}$. Parry, et $a l^{6}$, recently extending the review, also identified several flare characteristics beyond pain exacerbation. 
The concept of flare was defined in previous work on rheumatoid arthritis by an Outcome Measures in Rheumatology (OMERACT) group as "a cluster of symptoms of sufficient duration and intensity to require initiation, change or increase in therapy"7. It served as a guide for developing measurement instruments $8,9,10$.

Although sharing some characteristics such as temporary exacerbation of pain as one of its major components, whether this definition can also serve for defining flare in KHOA has to be examined.

The lack of a clear and agreed upon definition of a flare in $\mathrm{OA}$ underlines the need for a conceptual definition before developing a measurement instrument of flare as a patient-reported outcome (PRO) for clinical trials or longitudinal observational studies. Further, to meet the requirement for a valid measure, OMERACT Filter 2.0 mandates the need to first define core outcome domains before developing or choosing an instrument ${ }^{11}$. The Flare-in-OA Working Group (WG) initiative was endorsed by OMERACT and Osteoarthritis Research Society International (OARSI). Currently, flare is on the research agenda for core domain set of $\mathrm{KHOA}^{12}$.

Our paper reports on the generation and selection of relevant domains and components for flare in KHOA and a proposal for preliminary elements for a definition.

\section{MATERIALS AND METHODS}

An inductive approach was used simultaneously in 2 languages, i.e., French and English, with the goal of generating candidate domains labeled with multiple language understanding. Then, consensus building on the selection of the most relevant domains involved participants in 3 continents.

Generation of domains. Unstructured interviews with 10 patients were conducted initially to identify the whole experience of a flare and further generate a semistructured interview guide developed under the guidance of 2 senior health psychologists, and cross-validated across languages. This guide was used by health psychologists and health professionals (HP) fully trained in conducting such interviews in France and Australia to elicit the perception of flare characteristics from HP and patients separately.

People recruited for this investigative step were participants with OA ("patients") at the Royal North Shore Hospital (Australia), from the KHOALA cohort study (Knee and Hip OsteoArthritis Longitudinal Assessment) in France, and HP (nurses, physiotherapists, rheumatologists, general practitioners, orthopedic surgeons) from among OARSI members, and OMERACT working group members. The HP were from the same setting in Australia and from 5 centers in France.

The interviews were recorded, transcribed, and prepared for analysis with Nvivo software in parallel in each country. The content analysis allowed identification of statements obtained verbatim (expressions extracted from interviews) that were meaningful for HP and patients. The French statements were translated into English. Similar statements were grouped in clusters analyzing the same topics. Labels of each cluster were proposed as domain names.

The WG steering group (consisting of clinicians, methodologists, and health psychologists; see Acknowledgment) critically analyzed the clustering of statements and the proposed labeling of clusters based on secondary content examination of the transcripts, taking care to ensure cross-language equivalence.

Selection of domains. Delphi surveys were conducted in 2 rounds among patients from national settings from the SPARK study (Study of Risk Factors for Pain Exacerbation in Osteoarthritis of the Knee) and Arthritis Alliance, Australia, from STPR group centers in France, and from HP as well as scientists, as per OARSI membership. OMERACT rules for Delphi consensus building were applied at each round, i.e., a threshold of $70 \%$ agreement should be reached to make a decision ${ }^{13}$.

Final results of the 2 rounds in each group were presented at the OMERACT 2018 meeting to the WG through a virtual link for finalizing selection of core domains. Elements for a preliminary definition of a flare were identified according to the conceptual framework underlying these choices.

Ethics and consent. This research was approved by the national Institutional Review Board in France (CNIL DR-2015-134) and by the Human Research Ethics Committee at the University of Sydney, Australia. All patients and health professionals gave informed consent to participate in the research. Registered at clinicaltrials.gov NCT02892058.

\section{RESULTS}

Generating domains. Individual semistructured interviews with 29 patients and $16 \mathrm{HP}$ generated 180 statements specific to an OA flare. Content analysis involved grouping the statements into 9 clusters, which were labeled by names reflecting the covered topic (Supplementary Table 1 and Supplementary Table 2, available with the online version of this article). The WG steering group approved clustering and labeling of these topics.

Selecting domains. Participants in the Delphi survey were HP (researchers, rheumatologists, physiotherapists, orthopedic surgeons, nurses) from 17 countries on 4 continents, and patients were from Australia, Canada, and France.

During the first Delphi round, 91 patients rejected the domain "buckling."

In the second round, 50 patients retained 7 domains: pain, swelling, stiffness, triggers, consequences of the symptoms, psychological aspects, and protective factors. Two domains were rejected: buckling and other symptoms (Table 1).

In the first round, $165 \mathrm{HP}$ participated and rejected 2 domains: buckling and other symptoms. In the second round, 116 HP participated and retained 7 domains: pain, swelling, stiffness, triggers, consequences of the symptoms, psychological aspects, protective factors; and rejected 2 domains: buckling and other symptoms (Table 2).

Finally, the consensus reached by the OMERACT 2018 meeting participants was that:

(1) Pain, swelling, and stiffness domains were fully supported by both HP and patients;

(2) Buckling and other symptoms domains were removed by both HP and patients;

(3) The psychological aspects domain showed slightly discrepant results between patients (72\%) and HP (67.2\%) rating somewhat below the prespecified threshold. In keeping with new OMERACT guidance for reaching consensus ${ }^{13}$ that recommends a $70 \%$ threshold in either patient or combined other stakeholder groups, this domain was retained. Because flare is a patient perception that conditions healthcare use, it was considered relevant to weigh patients' opinions higher than those of others and retain this domain;

Personal non-commercial use only. The Journal of Rheumatology Copyright $\subset$ (2019. All rights reserved. 
Table 1. Selection of domains by patients in first $(\mathrm{n}=91)$ and second $(\mathrm{n}=50)$ Delphi rounds. Values are $\%$.

\begin{tabular}{lccccc}
\hline \multirow{2}{*}{ Domain } & \multicolumn{2}{c}{ First Delphi Round } & \multicolumn{2}{c}{ Second Delphi Round } \\
& $\begin{array}{c}\text { Must Be } \\
\text { Kept }\end{array}$ & $\begin{array}{c}\text { Could Be } \\
\text { Kept }\end{array}$ & $\begin{array}{c}\text { Could Be } \\
\text { Removed }\end{array}$ & $\begin{array}{c}\text { Must Be } \\
\text { Kept }\end{array}$ & $\begin{array}{c}\text { Must Be } \\
\text { Removed }\end{array}$ \\
\hline Pain (duration, severity, frequency) & 67.0 & 26.4 & 6.6 & 92.0 & 8.0 \\
Swelling & 47.3 & 36.3 & 16.5 & 78.0 & 22.0 \\
Stiffness & 59.3 & 33.0 & 7.7 & 90.0 & 10.0 \\
Buckling & 28.6 & 36.3 & 35.2 & 62.0 & 38.0 \\
Other symptoms & 24.2 & 47.3 & 28.6 & 52.0 & 48.0 \\
Triggers (tiredness, activity, movement) & 62.6 & 29.7 & 7.7 & 88.0 & 12.0 \\
Consequences of the symptoms (sleep, concentration, & & & & & \\
$\quad$ activity, need help, walking) & 60.4 & 33.0 & 6.6 & 88.0 & 12.0 \\
Psychological aspects (mood, annoyance, & & & & & \\
$\quad$ frustration) & 40.7 & 42.9 & 16.5 & 72.0 & 28.0 \\
Protective factors (rest, change of activity) & 56.0 & 35.2 & 8.8 & 90.0 & 10.0 \\
\hline
\end{tabular}

Table 2. Selection of domains by health professionals in first $(\mathrm{n}=165)$ and second $(\mathrm{n}=116)$ Delphi rounds. Values are $\%$.

\begin{tabular}{|c|c|c|c|c|c|}
\hline \multirow[t]{2}{*}{ Domain } & \multicolumn{3}{|c|}{ First Delphi Round } & \multicolumn{2}{|c|}{ Second Delphi Round } \\
\hline & $\begin{array}{l}\text { Must Be } \\
\text { Kept }\end{array}$ & $\begin{array}{l}\text { Could Be } \\
\text { Kept }\end{array}$ & $\begin{array}{l}\text { Could Be } \\
\text { Removed }\end{array}$ & $\begin{array}{c}\text { Must Be } \\
\text { Kept }\end{array}$ & $\begin{array}{r}\text { Must Be } \\
\text { Removed }\end{array}$ \\
\hline Pain (duration, severity, frequency) & 96.4 & 1.8 & 1.8 & 100 & - \\
\hline Swelling & 69.1 & 25.5 & 5.5 & 94.8 & 5.2 \\
\hline Stiffness & 58.2 & 32.7 & 9.1 & 88.8 & 11.2 \\
\hline Buckling & 18.2 & 46.1 & 35.8 & 23.3 & 76.7 \\
\hline Other symptoms & 13.9 & 47.9 & 38.2 & 25.0 & 75.0 \\
\hline Triggers (tiredness, activity, movement) & 51.5 & 35.2 & 13.3 & 78.4 & 21.6 \\
\hline $\begin{array}{l}\text { Consequences of the symptoms (sleep, con } \\
\text { activity, need help, walking) }\end{array}$ & $\begin{array}{l}\text { entration, } \\
57.6\end{array}$ & 35.8 & 6.7 & 95.7 & 4.3 \\
\hline $\begin{array}{l}\text { Psychological aspects (mood, annoyance, } \\
\text { frustration) }\end{array}$ & 38.2 & 46.1 & 15.8 & 67.2 & 32.8 \\
\hline Protective factors (rest, change of activity) & 47.3 & 39.4 & 13.3 & 79.3 & 20.7 \\
\hline
\end{tabular}

(4) Triggers domain, endorsed by both HP and patients in the Delphi survey, was finally removed because further discussion determined that this domain reflected possible causes of the flare rather than the flare itself;

(5) Consequences of the symptoms and protective factors were endorsed by both HP and patients, but the meeting participants advised to merge them into 1 domain called impact of the symptoms, because "protective factors" was considered to be a behavioral protection adopted when the flare occurred as an attempt to limit its effect (such as resting, changing activity).

From the discussion at OMERACT 2018, several elements emerged from this framework for setting a preliminary definition of a flare in KHOA: it is a transient state, different from the usual state of the condition, with a duration of a few days, characterized by onset, worsening of pain, swelling, stiffness, impact on sleep, activity, functioning, and psychological aspects that can resolve spontaneously or lead to a need to adjust therapy.

\section{DISCUSSION}

From a large number of statements, 5 core domains characterizing a flare in KHOA were selected based on consensus by patients, HP, and OA researchers. Their final selection took care to avoid missing important but rare manifestations and accounted for health providers having a comprehensive view of the disease combined with patients' statements of their actual experience.

The advantage of conducting domain definition and choice using an inductive approach was that domain labeling was informed by patients' statements extracted verbatim from qualitative research. Such a bottom-up approach gives accuracy and relevance to the domain labeling, which is usually the first way people approach a questionnaire to assess content (face validity). This helped the generation of candidate domains in developing a conceptual framework through an inductive approach.

Our proposed preliminary definition has several points in common with previous attempts to define OA flare in the 
literature. Several experts on the committee participated in previous qualitative work conducted to understand the pain experience in $\mathrm{OA}^{14}$. Flare was characterized as a state different from the patient's usual condition. Parry, et $a l^{6}$ proposed focusing on onset/worsening of symptoms and signs, attainment of a minimum symptom threshold during flare, speed of onset/worsening, and duration of elevated symptoms/signs, while Murphy, $e t a l^{3}$ reported pain flares were common, fleeting, and often experienced in the context of activity engagement. These definitions and ours are convergent, with some differences, e.g., about onset mode, and require further refinement before a final definition is accepted.

Only 2 languages were used to generate domains, which might leave the meaning of domain labels uncertain for further translation. Such initiative at the very beginning of a data-driven approach is not common ${ }^{15}$, leading to careful examination of the meaning of the domain labels and their correct correspondence with statements generated from patients, which could be helpful for translation into other languages. Another limitation was that the Delphi process missed some relevant stakeholders (i.e., regulators, industry).

This work provides a framework for defining a flare in KHOA and identified domains that form the basis for developing items for a patient-reported outcome instrument that incorporates components relevant to OA flare.

\section{ACKNOWLEDGMENT}

Working Group (WG) Steering Group: Annica Barcenilla-Wong, Marita Cross, Francis Guillemin, David J. Hunter, Lyn March, Camille Ricatte, Claudia Rutherford, Amandine Schoumacker, Elisabeth Spitz. WG Chair: Francis Guillemin, Gillian Hawker, David J. Hunter, Lyn March (OMERACT mentor). Collaborator: Joanna Makovey, Sydney, Australia. We thank the Osteoarthritis Research Society International (OARSI) members, health professionals, and people who participated in the various stages of this work, and Joanna Makovey, Sydney, for facilitating communication regarding the project.

\section{ONLINE SUPPLEMENT}

Supplementary material accompanies the online version of this article.

\section{REFERENCES}

1. GBD 2016 Disease and Injury Incidence and Prevalence Collaborators. Global, regional, and national incidence, prevalence, and years lived with disability for 328 diseases and injuries for 195 countries, 1990-2016: a systematic analysis for the Global Burden of Disease Study 2016. Lancet 2017;390:1211-59.
2. Cross M, Smith E, Hoy D, Nolte S, Ackerman I, Fransen M, et al. The global burden of hip and knee osteoarthritis: estimates from the global burden of disease 2010 study. Ann Rheum Dis 2014;73:1323-30

3. Murphy SL, Lyden AK, Kratz AL, Fritz H, Williams DA, Clauw DJ, et al. Characterizing pain flares from the perspective of individuals with symptomatic knee osteoarthritis. Arthritis Care Res 2015;67:1103-11.

4. Cross M, Dubouis L, Mangin M, Hunter DJ, March L, Hawker G, et al. Defining flare in osteoarthritis of the hip and knee: a systematic literature review - OMERACT virtual special interest group. J Rheumatol 2017;44:1920-7.

5. Marty M, Hilliquin P, Rozenberg S, Valat JP, Vignon E, Coste P, et al. Validation of the KOFUS (Knee Osteoarthritis Flare-Ups Score). Joint Bone Spine 2009;76:268-72.

6. Parry EL, Thomas MJ, Peat G. Defining acute flares in knee osteoarthritis: a systematic review. BMJ Open 2018;8:e019804.

7. Bingham CO 3rd, Pohl C, Woodworth TG, Hewlett SE, May JE, Rahman MU, et al. Developing a standardized definition for disease "flare" in rheumatoid arthritis (OMERACT 9 Special Interest Group). J Rheumatol 2009;36:2335-41.

8. Berthelot JM, De Bandt M, Morel J, Benatig F, Constantin A, Gaudin P, et al; STPR group of French Society of Rheumatology. A tool to identify recent or present rheumatoid arthritis flare from both patient and physician perspectives: the 'FLARE' instrument. Ann Rheum Dis 2012;71:1110-6.

9. Fautrel B, Morel J, Berthelot JM, Constantin A, De Bandt M, Gaudin P, et al; STPR Group of the French Society of Rheumatology. Validation of FLARE-RA, a self-administered tool to detect recent or current rheumatoid arthritis flare. Arthritis Rheumatol 2017;69:309-19.

10. Bartlett SJ, Barbic SP, Bykerk VP, Choy EH, Alten R, Christensen $\mathrm{R}$, et al. Content and construct validity, reliability, and responsiveness of the rheumatoid arthritis flare questionnaire: OMERACT 2016 workshop report. J Rheumatol 2017;44:1536-43.

11. Boers M, Kirwan JR, Wells G, Beaton D, Gossec L, d'Agostino MA, et al. Developing core outcome measurement sets for clinical trials: OMERACT filter 2.0. J Clin Epidemiol 2014;67:745-53.

12. Smith TO, Hawker GA, Hunter DJ, March LM, Boers M, Shea BJ, et al. The OMERACT-OARSI core domain set for measurement in clinical trials of hip and/or knee osteoarthritis. J Rheumatol 2019;46:981-9.

13. Boers M, Kirwan JR, Tugwell P, Beaton D, Bingham CO III, Conaghan PG, et al. The OMERACT Handbook. [Internet. Accessed April 11, 2019.] Available from: https://omeract.org/resources

14. Hawker GA, Davis AM, French MR, Cibere J, Jordan JM, March L, et al. Development and preliminary psychometric testing of a new OA pain measure - an OARSI/OMERACT initiative. Osteoarthritis Cartilage 2008;16:409-14.

15. The World Health Organization Quality of Life assessment (WHOQOL): position paper from the World Health Organization. Soc Sci Med 1995;41:1403-9. 